\title{
The PREVIEW Global Risk Data Platform: a geoportal to serve and share global data on risk to natural hazards
}

\author{
G. Giuliani ${ }^{1,2,3}$ and P. Peduzzi ${ }^{1,3,4}$ \\ ${ }^{1}$ United Nations Environment Programme, Division of Early Warning and Assessment, Global Resource Information \\ Database - Europe, Geneva, Switzerland \\ ${ }^{2}$ University of Geneva, Institute of Environmental Sciences, Climatic Change and Climate Impacts, enviroSPACE, \\ Geneva, Switzerland \\ ${ }^{3}$ University of Geneva, Forel Institute, Geneva, Switzerland \\ ${ }^{4}$ Institute of Geomatics and Risk Analysis (IGAR), University of Lausanne, Lausanne, Switzerland
}

Received: 11 May 2010 - Revised: 30 September 2010 - Accepted: 6 November 2010 - Published: 5 January 2011

\begin{abstract}
With growing world population and concentration in urban and coastal areas, the exposure to natural hazards is increasing and results in higher risk of human and economic losses. Improving the identification of areas, population and assets potentially exposed to natural hazards is essential to reduce the consequences of such events. Disaster risk is a function of hazard, exposure and vulnerability. Modelling risk at the global level requires accessing and processing a large number of data, from numerous collaborating centres.

These data need to be easily updated, and there is a need for centralizing access to this information as well as simplifying its use for non GIS specialists. The Hyogo Framework for Action provides the mandate for data sharing, so that governments and international development agencies can take appropriate decision for disaster risk reduction.

Timely access and easy integration of geospatial data are essential to support efforts in Disaster Risk Reduction. However various issues in data availability, accessibility and integration limit the use of such data. In consequence, a framework that facilitate sharing and exchange of geospatial data on natural hazards should improve decision-making process. The PREVIEW Global Risk Data Platform is a highly interactive web-based GIS portal supported by a Spatial Data Infrastructure that offers free and interoperable access to more than 60 global data sets on nine types of natural hazards (tropical cyclones and related storm surges, drought, earthquakes, biomass fires, floods, landslides, tsunamis and volcanic eruptions) and related exposure
\end{abstract}

Correspondence to: G. Giuliani (gregory.giuliani@unepgrid.ch) and risk. This application portrays an easy-to-use online interactive mapping interface so that users can easily work with it and seamlessly integrate data in their own data flow using fully compliant OGC Web Services (OWS).

\section{Introduction}

The Hyogo Framework for action, priority two, states that "The starting point for reducing disaster risk and for promoting a culture of disaster resilience lies in the knowledge of the hazards and the physical, social, economic and environmental vulnerabilities to disasters [...] followed by action taken on the basis of that knowledge". Parts of this priority consist in "producing risk assessment and maps, producing indicators on Disaster Risk Reduction (DRR) and vulnerability, data sharing" (UNISDR, 2005). Moreover, the Agenda 21 resolution fosters the importance of having readily accessible, available, and exchangeable appropriate information as a condition to create the basis of a sustainable development that supports information management needs to implement and monitor related policies and goals such as the Millennium Development Goals (Nebert, 2005).

This means that there is a clear mandate to make data easily available and accessible in order to give users and stakeholders the opportunity to turn data into useable and understandable information. Achieving the objectives of both sustainable development and DRR requires the integration of a large number of different data types coming from various sources.

Published by Copernicus Publications on behalf of the European Geosciences Union. 
Through agreed common standards and a clear political will, these data can be interchanged and integrated in an interoperable way, leading to a new collaborative approach in decision-making.

Although administrations and governments recognize that spatial information is important and must be effectively managed and coordinated for the interest of all citizens (Ryttersgaard, 2001), geospatial data are often stored in different formats, based on different units and projections, located in different places, and managed by different organizations with different policies. In consequence, these issues impede an efficient and effective use of these data (Alinia and Delavara, 2009; Rajabifard et al., 2004).

Spatial Data Infrastructures (SDIs) appear to be promising frameworks to facilitate interaction between users and geospatial data (Alinia and Delavara, 2009; Rajabifard et al., 2004) allowing one to share and exchange required information on disasters. Mansourian et al. (2006) consider Geographical Information Systems (GIS) as a tool that facilitates decision-making and disaster risk reduction, allowing to capture, manage, integrate, manipulate, analyze and visualize geospatial data made available by SDIs (Masser, 2007). In particular, web-based GIS portals, commonly known as geoportals, could be appropriate tools due to their high interactivity and accessibility, acting as gateways to relevant geospatial information (Tang and Selwood, 2005).

In 1999, at the end of the International Decade for Disaster Risk Reduction (IDNDR), United Nations Environment Programme/Global Resource Information DatabaseEurope (UNEP/GRID-Europe) initiated the Project for Risk Evaluation, Vulnerability, Information and Early Warning (PREVIEW). One component of this project was a standalone web-GIS, called PREVIEW-Internet Map Server (IMS), an application aiming at visualizing data through an "easy to use" web interface and to disseminate data in common GIS formats (shapefile ${ }^{1}$, grids ${ }^{2}$ ) with static zip files. It was based on the first generation of interactive mapping, developed with ESRI MapObject, (HTML and Visual Basic code). This application met with a good success, allowing users to access these data in a simple way; it ran without problem from August 2000 to May 2009.

Between 2001 and 2004, UNEP/GRID-Europe developed the Disaster Risk Index (DRI) for United Nations Development Programme/Bureau of Crisis Prevention and Recovery (UNDP/BCPR) (UNDP, 2004; Peduzzi et al., 2009a). This extensive study was the first to compute exposure and risk for four natural hazards (cyclones, droughts, floods and earthquakes) at the global level. These data sets were made available for visualization and download through PREVIEWIMS and were used by different institutions such as the

\footnotetext{
${ }^{1}$ http://www.esri.com/library/whitepapers/pdfs/shapefile.pdf

${ }^{2} \mathrm{http}: / /$ resources.arcgis.com/content/kbase?fa=articleShow $\backslash$ $\& d=30616$
}

UN Office Coordination for Humanitarian Affairs (OCHA). Some the data from PREVIEW (volcanic eruption and tropical cyclones) were also used by the World Bank for their study "Hotspots" (Dilley et al., 2005).

With the availability of new data and more powerful computational capacity, a major improvement of these datasets was carry on by United Nations Environment Programme (UNEP/GRID-Europe), United Nations International Strategy for Disaster Reduction (UNISDR), Norwegian Geotechnical Institute (NGI) amongst others. This include the generation of new data sets for hazards distribution (cyclones, droughts, earthquakes, floods, biomass fires, landslides and tsunamis) with different intensities, computation of the human and economical exposures and computation of risk for cyclones, floods, earthquakes and landslides. All these data were included into a webbased GIS portal supported by a SDI that gives free and interoperable access to global data sets on natural hazards and related exposure and risk. These developments were made for the 2009 Global Assessment Report on Disaster Risk Reduction (UN, 2009; Peduzzi et al., 2009b, 2010).

This application is currently supported by UNEP and UNISDR. The data included in this platform is the result of a two-year research effort. These UN organizations have the mandate and the willingness to share this information in a free and open way, so that anybody may access data and hopefully contribute to its improvement.

This paper aims to describe the development of the webbased geoportal called PREVIEW Global Risk Data Platform (replacing PREVIEW-IMS) together with its associated SDI to support and facilitate geospatial data discovery, accessibility, visualization, and dissemination regarding past hazardous events, human and economical exposure, as well as risk maps from natural hazards. This application can be accessed at http//:preview.grid.unep.ch.

\section{SDI and its role for Disaster Risk Reduction community}

The Disaster Risk Reduction community works through several organizations/participants during its whole cycle of activities ranging from emergency units (e.g. fire, medical and police) up to government bodies. In an emergency situation, people involved need timely, reliable and up-todate information in order to provide an efficient and effective response (Mansourian et al., 2006; Rajabifard et al., 2004) while at the same time, returning new information on a specific situation. In other words, they are users as well as producers/updaters of important information. Moreover, because of the diversity of participants and the variety of information required for a disaster response, no single organization could collect and maintain all the required data sets (Mansourian et al., 2006). Thus, recognizing that once data has been produced it could be used by different 
stakeholders (Ryttersgaard, 2001) reinforced the need to store data into databases that are made largely accessible and available for different purposes (Philips et al., 1999). This leads to the concept that geospatial data could be a shared resource that will be maintained continuously. In summary, having geospatial data in digital form allows easy storage into databases and file systems, facilitates data exchange/sharing, faster updates, gives the ability to integrate data from multiple sources, and finally favours developing customized products and services (Nebert, 2005).

From the previous considerations it could be argued that a collaborative environment based on the concept of partnership in data production, management, and integration would bring major benefits (Alinia and Delavara, 2009; Mansourian et al., 2006). As a result, the concept of SDI seems to be an interesting framework to facilitate and coordinate the exchange and sharing of geospatial data (Masser, 2007; Rajabifard and Williamson, 2001) encompassing data sources, systems, network linkages, standards and institutional issues in delivering geospatial data and information, from many different sources to the widest possible group of potential users (Coleman et al., 1997). For Alinia and Delavar (2009) such a framework where people and geospatial data could interact offers an appropriate support for decision-making and disaster response objectives through improving availability, accessibility and applicability of geospatial data. SDIs intend to avoid duplication of efforts and expenses by enabling users to save resources, and time when trying to acquire or maintain data sets (Mansourian et al., 2004; Rajabifard and Williamson, 2001). Finally SDIs can be seen as an integrated information highway which links together environmental, socio-economic and institutional geospatial data resources providing a movement of data from local to national and global levels (Masser, 2005a; Rajabifard and Williamson, 2001). Successful implementations of SDI frameworks for disaster management purposes have already been tested in different case studies such as wild fire risk assessment used by the Italian civil protection (Mazzetti et al., 2009), evacuation scenario after a bomb threat (Weiser and Zipf, 2007) or disaster management in Iran (Mansourian et al., 2005; Mansourian et al., 2006). All these authors consider and demonstrate that SDIs associated with tools like GIS and/or web-based services have a great potential in helping disaster community to effectively and efficiently manage disaster response, and allowing decisionmakers to have permanent access to reliable and up-to-date geospatial data.

\section{The PREVIEW Global Risk Data Platform}

As part of Global Assessment Report on Disaster Risk Reduction $^{3}$ (GAR) 2009 activities, the PREVIEW Global Risk Data Platform (http://preview.grid.unep.ch) was developed to allow different users to visualize risk distribution and provide easy access to geospatial data sets on global risk from natural hazards.

With the initiation of the GAR process in 2007, it was clear that PREVIEW-IMS had to be updated and extended using recent advancements in geospatial technology. In the meantime, SDI concept has matured and was endorsed in different countries as well as in different communities dealing with geospatial data (Masser, 2007). In consequence, SDI appeared to be a rationale choice to extend and reinforce capabilities of PREVIEW. Sharing all scientific data produced during the project was a primary objective since its beginning by making them visible to the largest possible audience and to promote the concept of data reusability. Moreover, to emphasize this "open and sharing spirit" PREVIEW was entirely developed using free and open source software, with the aim of facilitating its replication at national and/or local levels in developing countries. This choice was also justified by the fact that most countries experiencing high risk from natural hazards have medium to low human development and in general are looking with interest to free and open source technologies. In addition the Policies of the United Nations System Organizations Towards the Use of Open Source Software (OSS) for Development JIU/REP/2005/7, stated that "OSS has been recognized in many instances to be a valid alternative to corresponding proprietary software, such recognition should be reflected in Member States' ICT policies for development. [...] The open standardsbased notional information architecture envisaged by UNEP is a vendor-neutral, interoperable platform that needs to work effectively with the services run by its partners inside and outside the UN" (Henricksen, 2007).

In consequence, having such an open source platform readily available to be deployed in these countries is a strong incentive for capacity building, knowledge transfer, and sharing of expertise.

As already mentioned earlier, and highlighted by Asante et al. (2006), integrated geospatial data are extremely valuable and data integration may contribute to adoption of long range actions to manage risk. The GAR 2009 report focused its attention on disaster risk patterns, trends and drivers at global scale allowing identifying geographical distribution and concentration of risk across countries (UN, 2009). In particular having means to easily communicate risk information to exposed communities will improve the different phases of disaster management. In these regards, the

\footnotetext{
${ }^{3}$ http://www.preventionweb.net/english/hyogo/gar/
} 


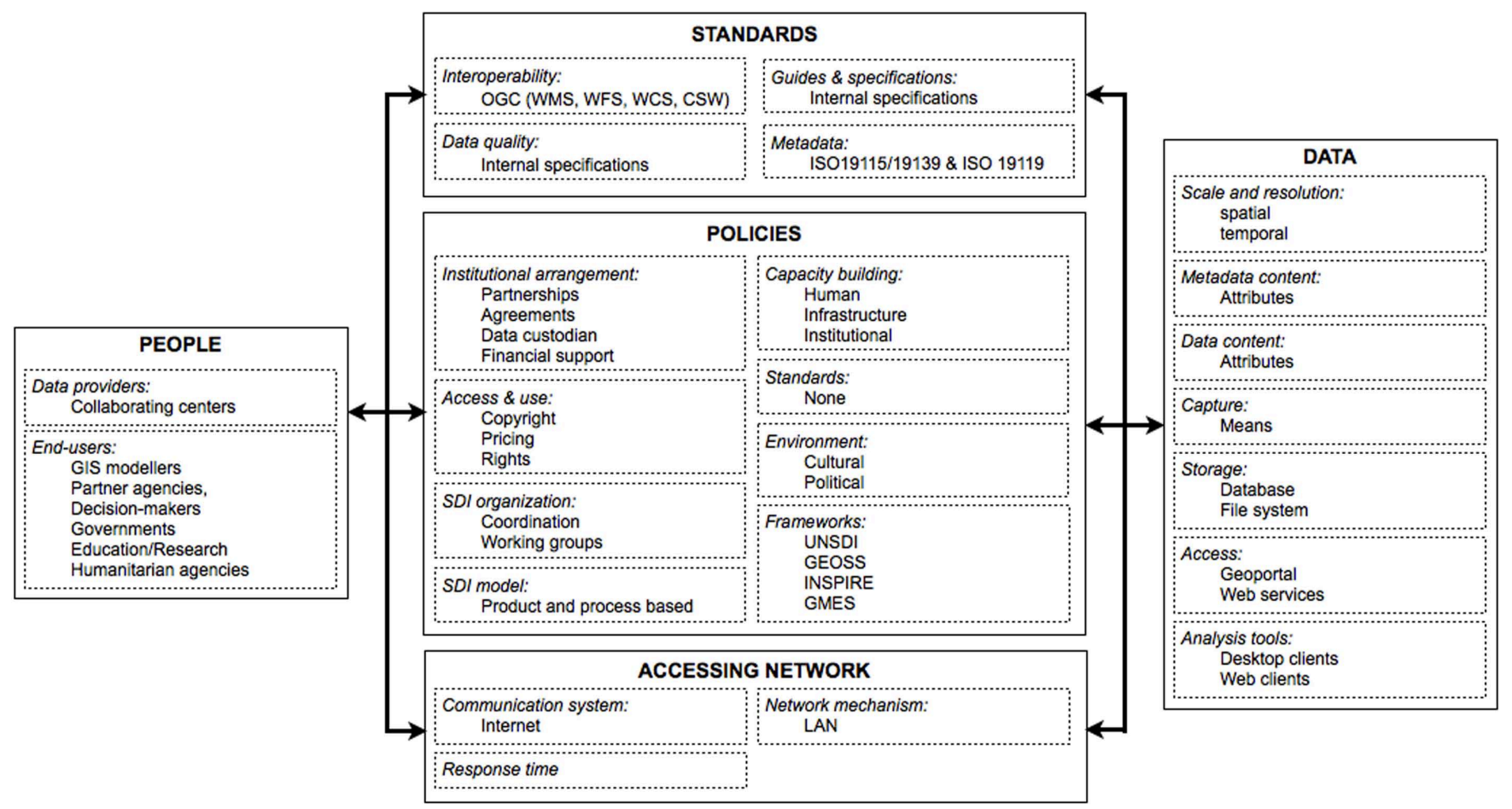

Fig. 1. PREVIEW SDI conceptual model (adapted from Mansourian et al., 2006; Rajabifard, 2002).

PREVIEW concentrates on visualization and dissemination of such data targeting more specifically prevention and awareness raising.

Considering SDIs as a collaborative environment that fosters activities for using, managing, producing and sharing geospatial data in which different stakeholders can cooperate and interact with technology to achieve their own objectives (Rajabifard and Williamson, 2001), the first step is to define a conceptual model to clearly identify the different components involved. Indeed, Nebert (2005) reported that the existence of geospatial data does not alone ensure that it is used for decision-making. Other factors must be considered so that data will be effectively used. Users need to know that a specific data set exists and where to obtain it, they need to be authorized to access and use it, and finally they need to know its history allowing them to interpret it, trust it and integrate it meaningfully with data coming from other sources. Rajabifard (2002) identifies five core components (people, data, standards, policies and accessing network) divided into two categories depending on the nature of their interactions within SDI environment. People and data constitute the first category while the second is composed of technological components. This vision highlights the dynamic nature of these categories: evolving technology, changing data requirements, improved data sets, changes within user communities, and changes in policies. Altogether these different components interact, influencing each others, and evolving continuously. Describing these different components (Fig. 1) will ensure a good and consistent implementation of SDI addressing different issues (e.g. standards to use, policies/agreements and communication means) facilitating the relation between people and data (Mansourian, et al., 2005), enhancing availability, accessibility and usage of geospatial data to support and improve decision-making process (Snoeren et al., 2007).

\section{PREVIEW SDI conceptual model}

The developed PREVIEW SDI conceptual model is based in part on the experience and knowledge acquired through the first generation of the PREVIEW application. In particular, People and Data components were well-known.

\subsection{People component}

Two categories (data providers and end-users) of the People component were clearly identified: data providers are the network of collaborating centres of the GAR and PREVIEW projects that give access to their data. End-users are alreadyknown and/or are targeted users that could potentially use data produced by the project. This corresponds to United Nations development agencies (e.g. UNISDR, UNDP, World Bank), humanitarian action (e.g. OCHA, Red Cross) or specialized agencies (e.g. UNEP, World Meteorological 
Organization - WMO, United Nations Educational, Scientific and Cultural Organization - UNESCO, World Health Organization - WHO, Food and Agriculture Organization - FAO, United Nations High Commissioner for Refugees - UNHCR), as well as decision-makers and governments that wish to have good and consistent data to take sound decisions. Finally such data are obviously useful for education in general and for scientists specialized in natural hazards and related risk in particular.

Currently most of the platforms that share and disseminate data on natural hazards use static download from a webpage or in the best case provide a File Transfer Protocol (FTP) access. Such capabilities are exemplified by the Hotspots project from the Center for Hazards and Risk Research (http: //www.ldeo.columbia.edu/chrr/research/hotspots/). Moreover they provide often access to hazard maps through PDF or image files. This is a common way within UN agencies to disseminate maps in this way like ReliefWeb from OCHA (http://www.reliefweb.int/) and UNOSAT (http://unosat.web. cern.ch/unosat/). This is certainly useful for people that are working on the field but clearly impede an interoperable access to data and create difficulties in updating information. Nevertheless there are a lot of web applications that allow visualization of data on hazards: some are concerned by a specific hazard type at a specific scale like the European Flood Alert System (EFAS, http://floods.jrc.ec.europa.eu/ efas-flood-forecasts), some concentrate on the access to real-time information like the Global Disaster Alert and Coordination System (GDACS, http://www.gdacs.org/), and some are at the global scale but only for a few hazards types and without possibilities to access/download the data like National Geophysical Data Center (NGDC, http://www. ngdc.noaa.gov/hazard/) or the United States Geological Survey (USGS) Geologic Hazards Science Center (https: //geohazards.cr.usgs.gov/). Finally, some platforms focus their attention on acquiring and disseminating data at the sub-national/local level. A good example of such a platform is DesInventar (http://www.desinventar.org) that provides users different web tools to visualize (maps, graphs, tables), query and analyze data. In summary, most of the current platforms concentrate on data visualization on specific hazard type and/or at a specific scale with limited capabilities to download/share data and metadata in an interoperable way.

In regard to the previous considerations and to our knowledge the unique value offered by PREVIEW is that it provides users an interactive and almost full access to harmonized, interoperable and fully documented data sets on multiple hazards at the global scale.

\subsection{Data component}

Data shared by PREVIEW are of two types: recorded past events in vectorial format (point, line or polygons) and results of the models used to compute hazards frequency, severity, human/economical exposures and risk in raster format (array of grid cells containing the value of the attribute to map).

In absence of a commonly agreed data models within disaster community, one of the first step of the project was to develop a common set of specifications for each data category (e.g. cyclones, earthquakes, floods). After the collection of events data sets, a general assessment was conducted to evaluate their differences in term of metadata, data formats, data attributes, projections, terminology, and naming conventions. At this stage, it has been observed that these data sets were very heterogeneous. Much of them were not documented with metadata, projections were different, attributes names and content were very different from one data set to another, and finally sometimes reference systems were missing. Nevertheless, all data providers give access to their data in a common format (shapefile). Hence, a general conceptual data model was defined to harmonize these data sets that will further be used in the different models to compute frequency, exposures and risk. After several discussions with both data providers and end-users an agreement on the following points has been reached: (1) all data sets must have metadata using ISO19115/19139, (2) working at the global scale, the World Geodetic System (WGS) 84 (EPSG 4326) has been used as reference system, (3) a common spatial resolution of $1 \mathrm{~km}$ appears to be a reasonable choice (because of the resolution of input data sets, such as population distribution, and the fact that output data are at global scale), (4) a common temporal resolution for events data sets (ranging from 1970 to 2009), (5) a glossary has been developed defining unambiguously different terms (e.g. cyclones, exposure, risk), (6) a set of general attributes has been defined for both input data sets (events) and results of models (frequency, exposures and risk maps), (7) a naming convention for data, attributes and versions has been created allowing an easy identification of the hazard type, data format, category (e.g. events, frequency, exposure or risk), and version, (8) finally, in order to overcome the problem of data formats, it has been decided to share and disseminate the data using interoperable data formats through OGC web services. All these different items were documented and available among data producers. Reaching such level of agreement has allowed to ease the quality check both for completness and accuracy, to update and harmonize input data sets (and create their metadata), to create a database accordingly specific constraints, to ease the production of new data from the different analytical models, and to ensure that all data producers use the same norms.

Data storage is in general achieved using database systems that allow a better management and control, and therefore will enhance data production and availability. It is important to note that following the choice of the database system, required functionalities and desired performance, it would be better to store raster data in a traditional file system. 
Finally, data access are given through a web-GIS portal, along with different kind of web services that enable users to retrieve data in interoperable way, using both web-based clients or desktop clients (like ArcGIS ${ }^{4}$ ).

\subsection{Standards component}

Once People and Data components have been defined, technological components were clarified in order to facilitate the interaction between users and data. The Standards component consists of four identified categories (interoperability, metadata, data quality, guides and specifications) aiming to ensure interoperable access to good quality data and metadata. In particular, interoperability is an essential task allowing different systems or components to exchange data through a common agreed system and to use data that has been exchanged. When systems are interoperable, it gives users the ability to find what they needs, access it, understand it, employ it and finally have tools and services responsive to their needs. As an answer to the need for interoperability, the Open Geospatial Consortium ${ }^{5}$ (OGC) has specified a suite of standards that allows interoperable access either to data or metadata. This allows users to retrieve, use and integrate geospatial data coming from different sources and stored in different formats using HTTP protocol to communicate. Web Feature Service (WFS) specification (Open Geospatial Consortium, 2005) gives access to vector data sets, while Web Coverage Service (WCS) gives access to raster data (Open Geospatial Consortium, 2006b). In addition, Web Map Service (WMS, Open Geospatial Consortium, 2006a) offers the ability to users to access georeferenced images of vectorial or raster data useful to display maps on the Web. To document data and related services through metadata, the International Organization for Standardization ${ }^{6}$ (ISO) 19115 (resource metdata) $^{7}, 19139$ (metadata encoding) $^{8}$ and $19119^{9}$ (service metadata) standards are widely used. In addition, the OGC provides a Catalog Service for the Web (CSW) specification (Open Geospatial Consortium, 2007) that complement these ISO standards, defining an interface to publish, discover, search and query metadata in an interoperable way. Metadata allows users to understand data quality, their history, interpret them, trust them and integrate them meaningfully with data coming from other sources (Nogueras-Iso et al., 2005). In consequence, quality standards and guides also appears important in order to ensure that data are produced with consistent and documented procedures (allowing replicability of methodologies)

\footnotetext{
${ }^{4} \mathrm{http}: / / \mathrm{www} . e s r i . c o m /$ software/arcgis

${ }^{5} \mathrm{http} / / / \mathrm{www}$. opengeospatial.org

${ }^{6} \mathrm{http}: / /$ www.iso.org

${ }^{7}$ http://www.iso.org/iso/iso_catalogue/catalogue_tc/ catalogue_detail.htm?csnumber $=26020$

${ }^{8} \mathrm{http} / / /$ www.iso.org/iso/catalogue_detail.htm?csnumber=32557

${ }^{9} \mathrm{http}: / /$ www.iso.org/iso/catalogue_detail.htm?csnumber=39890
}

and output data are of sufficient quality to be reliable (Mansourian et al., 2006). Indeed, data quality is an essential element in any geospatial implementation or application ensuring users to obtain meaningful results. For PREVIEW, four categories have been identified: (1) data completeness (amount of missing features), (2) data precision (degree of details), (3) data accuracy (degree to which data reflects correctly the real object) and (4) data consistency (usability of the data). These categories are assessed at two levels. The data producer that checks the quality of data based on given data specifications makes the first level. The second level is based on the users side that provide feedbacks that are taken into account to update/correct data.

\subsection{Network component}

From a technical point of view, the network is a critical element allowing people to effectively use data. This component facilitates the access to different geospatial data resources through access networks and interoperable services for cataloguing, searching, visualizing, and downloading geospatial data. In the case of PREVIEW, data should be accessible through the Internet and thus Local Area Network (LAN) is an important building block for that need. The different set of services offered by the platform is an another important element. They have been defined in the early stage of the development together with the suite of software used to publish data and metadata. In that sense, these services are basic components of a Service Oriented Architecture (SOA) that allow efficient access to spatially distributed data. The aim of an SOA is to promote loosely coupled, standardbased, protocol-independent distributed computing so that services can be reused as often as possible. These services are well defined set of actions, self contained, stateless, and do not depend on the state of other services. To support reusable deployment of services, OGC web services are based on the publish/find/bind pattern (Open Geospatial Consortium, 2004). In a simple scenario, a service provider hosts a web service and "publishes" a service description to a service broker. The service requester uses a "find" operation to retrieve the service description and uses it to "bind" with the service provider and invoke the web service itself. Such approach, based on reusable and standardized services, allows application development to be more focused by providing users just the functionality they need. Finally, performances/quality of services and in particular response time to a query is essential as users need to access data in a timely manner. For that purpose, each data set has been tested under varying load and requests conditions in order to tune services so that they can deliver a good quality of service under high workload conditions. 


\subsection{Policies component}

Finally, the Policies component is probably the most sensitive one as it must facilitate and encourage organizations to participate in the development of a SDI. Building a SDI is not only a matter of technology but first it relies on individuals and/or organizations. For Masser (2005b), building a SDI is a long term process that depends on support and commitment. Moreover, because of its multi-stakeholder nature, it is necessary to find a consensus to ensure measures of standardization and uniformity while recognizing the diversity and heterogeneity of the different participants that have different requirements to perform different tasks (Masser, 2006). As Fig. 1 shows, different categories are involved to fully describe this component. First of all, it is important to mention that building an efficient SDI is almost impossible without partnership because a single agency is unlikely to have all resources, skills or knowledge to undertake the development of all aspects of a SDI (Henricksen, 2007). In the case of PREVIEW, financial support was shared between UNISDR, UNEP and UNDP/BCPR. The authors (UNEP/GRID-Europe) did the scientific development of the SDI and the content was produced by UNEP/GRID-Europe with inputs from other scientific institutions such as Norwegian Geotechnical Institute (NGI) for landslides and tsunamis hazard modeling, and Columbia University for drought hazard modelling. The process also benefited from inputs of the United States Geological Survey (USGS) on earthquakes, Darthmouth Flood Observatory for identification of areas affected by past flood events, and European Space Agency (ESA) for fires detection (high temperature events). Finally UNESCO and WMO provided a reviewing process by 24 independent experts, who reviewed the methodologies for modeling the hazards. The methodologies for the development of the datasets and the results are not within the scope of this paper and will be described in a forthcoming paper (Peduzzi et al., 2010).

It was particularly important to reach agreements with data providers and partners agencies to develop a clear, coordinated, and committed vision to use, share and disseminate geospatial data (and related metadata) that were produced. This obviously covers issues like copyright, pricing and rights that influence directly access and use of data. In order to enhance the "open spirit" that guided the development of PREVIEW, almost all data sets on this platform are freely available and accessible. However, some institutions in the network still need to be convinced about providing free access to their data. The usual issue is financial: they might be willing to provide free access for research, while selling data to profit making institutions (e.g. re-insurance companies). Some data may also be only temporary protected (e.g. prior to publication). Finally, in other cases, the data providers agree to freely distribute their data, but prefer to do so through their own website instead of through the PREVIEW application. This is usually for visibility purpose and justification to financial support. In total, only four datasets (floods, tusnamis and volcanoes events; earthquakes shakemaps) out of the 60 layers provided by PREVIEW are not freely accessible/downloadable. Nevertheless they can be visualized and their metadata are available. Regarding metadata, data providers and partners agencies agree that they must be all freely available as they are essential to discover data and associated services. Hence, to be stored in the PREVIEW SDI, a data set must be documented with metadata (mandatory requirement).

We believe that previously mentioned situations are part of the transition phase that any new technology has to face. The sustained use of the platform should show the benefits to share data and reinforces the need to build new capacities by showing appropriate examples, sharing experiences and developing guidelines and policies. As the Group on Earth Observations (GEO) secretariat stated (GEO secretariat, 2006), capacity building should be made at three levels: human (education and training of individuals), infrastructure (installing/configuring/managing of the needed technology) and institutional (enhancing the understanding within organization and governments of the value of geospatial data to support decision-making). All these actions will help to reach endorsement on the use of such technologies, raising and increasing awareness on the benefits of using and sharing geospatial data, and finally creating new commitments. In addition, cultural and political aspects may influence either positively or negatively the acceptance and adoption of SDIs as a framework. Finally, different international initiatives at the regional (INSPIRE European Commission, 2007) and global scale (GEOSS, UNSDI, GMES) (GEO secretariat, 2005b; Henricksen, 2007) had a great influence on the development of PREVIEW. In particular, all partner agencies are part of the United Nations. In consequence, making these data available in the United Nations Spatial Data Infrastructure (UNSDI) framework (Henricksen, 2007) and registering to the Global Earth Observation System of Systems (GEOSS) (GEO secretariat, 2005a) is a de facto requirement for these agencies.

\section{PREVIEW Global Risk Data Platform, the gateway to global natural disaster data}

Key elements of any SDI are geoportals. Maguire and Longley (2005) define portals as gateways to an organized collection of resources (data, services, tools, links and documents) allowing an organization or a community to share specific content on the web. By extension, a geoportal can be seen as an entry-point to discover geospatial content. The OGC defines a common Geospatial Portal Reference Architecture (Open Geospatial Consortium, 2004) to support data sharing, discovery, visualization 


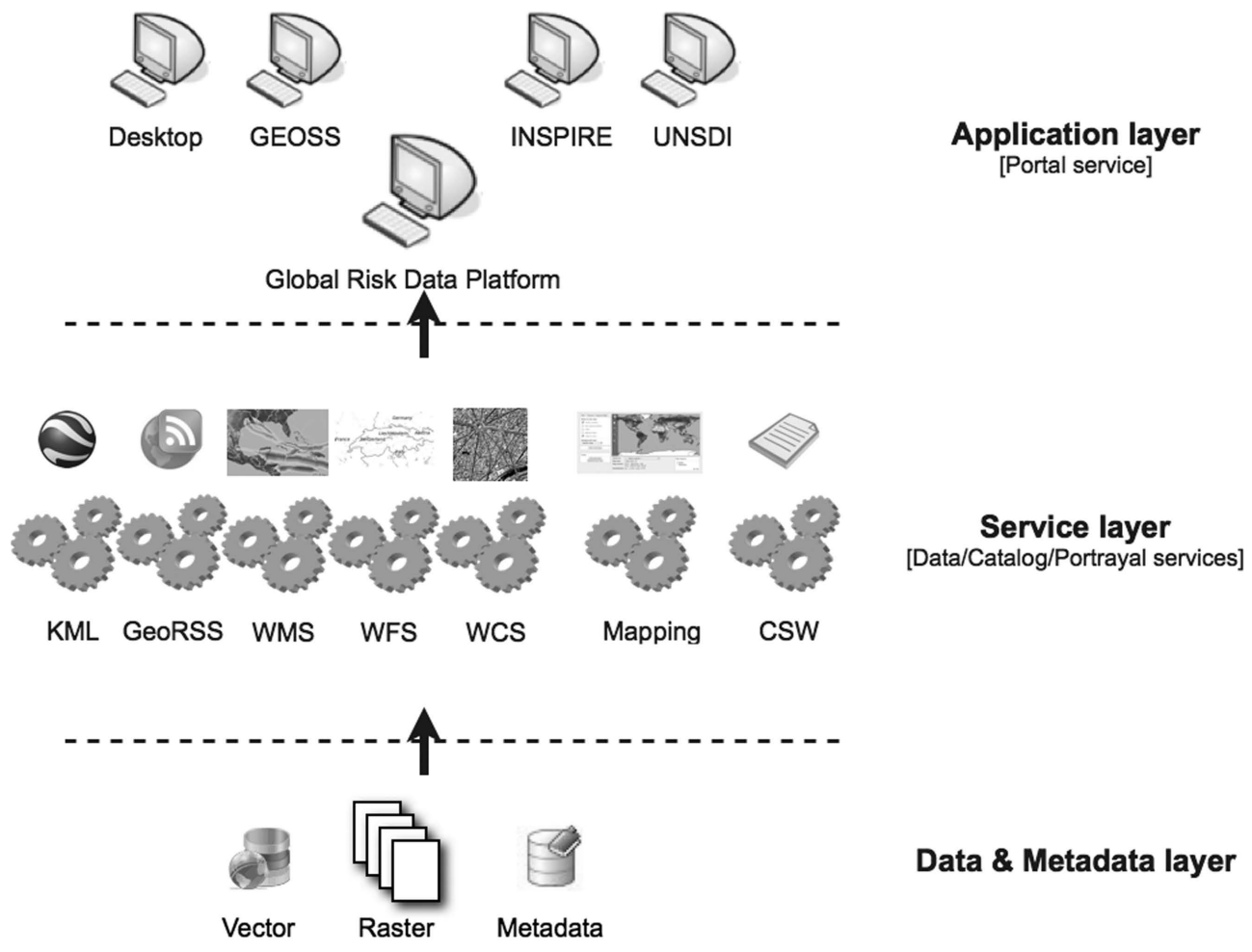

Fig. 2. PREVIEW Global Risk Data Platform data and metadata flow.

and retrieval. This architecture specifies four classes of services that are required to implement a geoportal using OGC interoperability standards: (1) portal service is the gateway to discover and access data as well as management and administration facilities; (2) catalog service offers information about data and related services; (3) portrayal service focuses on mapping and styling; and (4) data service provides data access and processing capabilities. To implement and deploy these different service classes, the OGC proposes to use web services technology giving access to distributed data and services through Uniform Resource Locators (URLs). This URL-based mechanism allows to publish standardized services over a network, typically the Internet, no matter how it is implemented (e.g. data format, storage) or on which platform it is executed. This leverages the real potential of interoperability by allowing web services to be seamlessly coupled, reusable and available for a wide variety of applications. In summary, the Geospatial Portal Reference Architecture mainly concerns the technological aspects (e.g. SOA, web services, standards) needed to implement a complete SDI model (data-standards-policiesnetwork-people components).

\subsection{System architecture}

The PREVIEW Global Risk Data Platform is then the portal service supported by PREVIEW SDI that aims to offer a simple user interface to freely visualize, access, download and extract geospatial data on natural disaster at the global scale. This OGC-compliant platform serves data through interoperable web services into GEOSS, UNSDI, Google Earth or other clients (web or desktop-based). Data and metadata are exposed through a set of interoperable services to different kind of applications following a three-tier model (Fig. 2).

Data and metadata layer is the level where all data sets and their related documentation are stored into a PostgreSQL ${ }^{10}$ database system. This allows to store metadata and vectorial data (using PostGIS ${ }^{11}$ extension) in this relational system benefiting from a set of tools to manage them efficiently. Raster data are stored in a well structured file system due to the current lack of support in PostGIS. Nevertheless, storing raster data in this way is not a limitation as they will be accessible through WCS. Service layer is an important element of the architecture as it implements most of the services defined by the Geospatial Portal Reference Architecture. Data and portrayal services are published using GeoServer ${ }^{12}$. This allows to publish data using OGC Web Services (OWS) such as WMS, WFS and WCS. In addition, Keyhole Markup Language ${ }^{13}$ (KML, to publish

\footnotetext{
${ }^{10} \mathrm{http}: / /$ www.postgresql.org

${ }^{11} \mathrm{http}: / /$ postgis.refractions.net

${ }^{12} \mathrm{http}: / /$ www.geoserver.org

${ }^{13} \mathrm{http} / / /$ www.opengeospatial.org/standards/kml/
} 


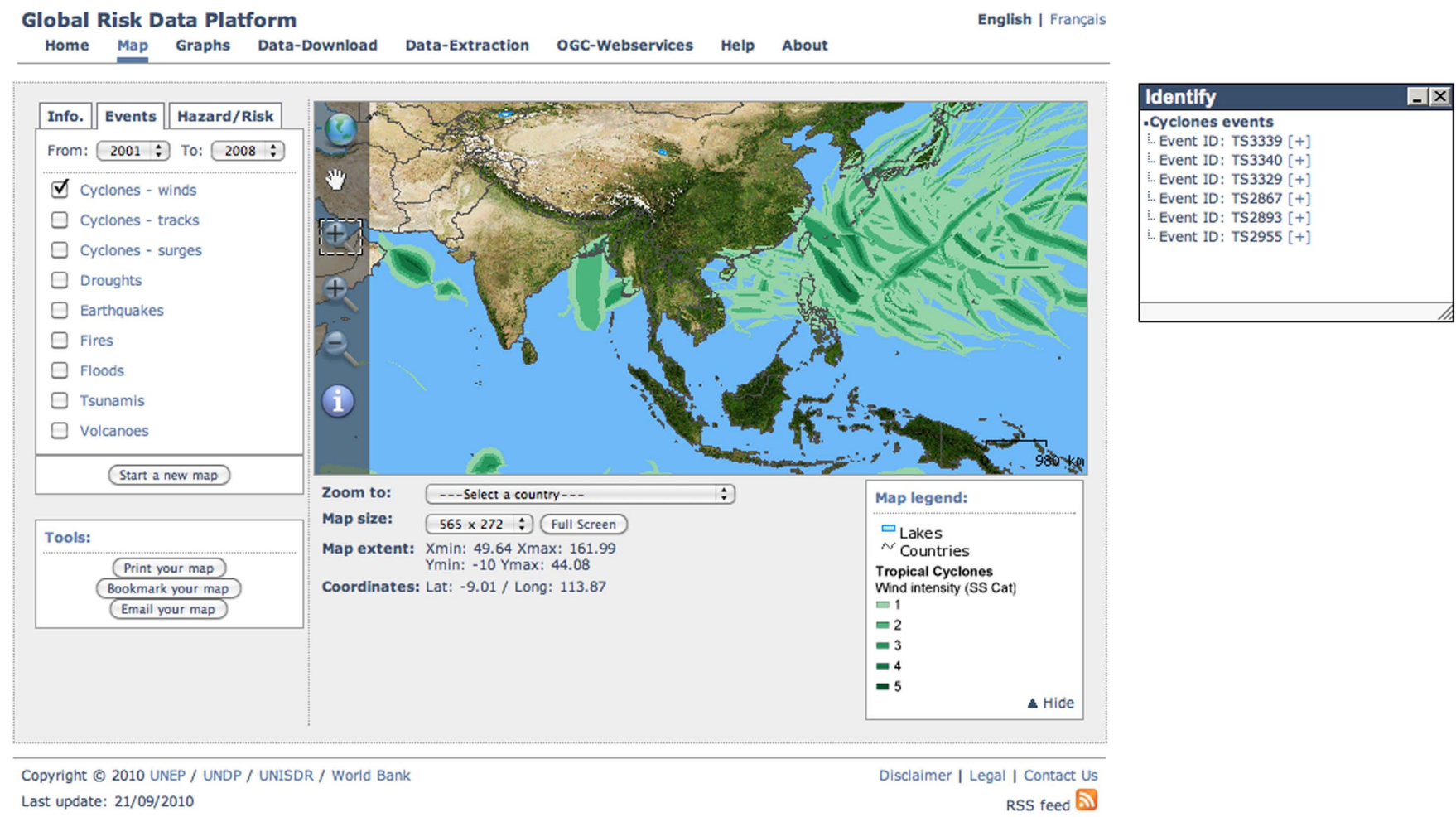

Fig. 3. Cyclones events from 2001 to 2008 in Asia as seen in the PREVIEW Global Risk Data Platform.

data into Google Earth) and GeoRSS ${ }^{14}$ (a geo-enabled RSS feed) are also provided. On the same basis, catalog service is exposed using GeoNetwork ${ }^{15}$ that implements CSW specification allowing users to search, query, discover, publish, and manage metadata on the different data layers. This further enhance visibility and sharing capacities of PREVIEW. Finally, a mapping service is published using UMN Mapserver ${ }^{16}$ allowing the web-based application to access different GIS capabilities. The application layer is the last tier where all the data and metadata should be accessible through the set of services provided by the service layer. The portal service is exposed through a specific web-based GIS application that presents data, catalog and portrayal services in a good and consistent way, offering users a single entry-point where they can easily work with, and seamlessly integrate, data in their own dataflow. These interoperable services are also accessible through other web applications (such as partners or other UN/non-UN agencies) or desktopGIS clients like ArcGIS. This allows users to work directly with data without the necessity to download and eventually change the formats to work with.

\footnotetext{
${ }^{14}$ http://georss.org/

$15 \mathrm{http} / / /$ geonetwork-opensource.org/

$16 \mathrm{http}: / /$ www.mapserver.org
}

\subsection{Geoportal functionalities}

This web-GIS application, written in $\mathrm{PHP}^{17}$ with the UMN Mapserver mapscript extension, offers a highly interactive access to up to 60 data layers based on five core modules:

1. Mapping module (Fig. 3): provides traditional web-GIS tools (zoom-in/out, full extent, pan) and the possibility to create its own map, to export it as a PDF file or share it with a bookmark and/or URL to copy/paste into an email.

2. Graph module: offers the ability to plot different graphs presented in the GAR report and interact with them (e.g. zoom, identify a specific country). Moreover, by clicking on a specific country supplemental information can be accessed through disaster risk country profiles provided by UNISDR system website.

3. Data download module: offers the possibility to explore, discover and access data. Each layer is presented on a page providing a complete overview at once. This gives access to the metadata, a preview of the data and its attributes (in the case of vector data), the different URLs of associated OGC web services

\footnotetext{
${ }^{17} \mathrm{http}: / /$ www.php.net
} 
and finally a traditional download capability. Users can chose a specific GIS data format for download. The data will be dynamically generated in the selected format with its associated metadata in an ISO19115/19139compliant XML file and made available for download in a zip file.

4. Data extraction module: gives the possibility to extract either vector or raster data for a specific country or region. This ensures the same geographical extent to all selected data sets and allows users to work only within a specific area.

5. OGC web services module: this module offers for each web service (WMS, WFS, WCS, KML and GeoRSS), the URL of the selected service to use in desktop clients and the URL generator for web-mapping application. Indeed, these URLs are in general complex and required different arguments (such as bounding boxes, type of request, format). Offering a simple access to these different request parameters should help users to implement these services into their own web applications.

\subsection{User-testing phase}

To ensure that this geoportal is easily usable, a two-day user testing phase has been set up, before the official launch of the application with the help of UNISDR information unit. Different users from various organizations (academia, partner agencies, humanitarian agencies, decision-makers) involved in disaster management community were invited to test PREVIEW through distinct proposed scenarios (e.g. create a map that shows the risk map for Cuba regarding tropical cyclones). This testing has shown the clear interest and benefits for participants in using such a platform. They have found it easy to use in producing maps and accessing data. Moreover, this phase also pointed out some inconsistencies, problems (e.g. legend, tools names) and bugs as well as the need for new functionalities (e.g. need of clear definitions, a tool to zoom on a specific country) that have been implemented and/or corrected immediately after the testing phase.

\section{Uses of the PREVIEW and lessons learnt}

The PREVIEW Global Risk Data Platform is accessible through the websites of the partners institutions (UNEP/GRID-Europe ${ }^{18}$, UNISDR Preventionweb ${ }^{19}$, UNDP/BCPR GRIP website ${ }^{20}$ ). It is also accessible through GEOSS as well as through other geoportals (e.g. UNHCR).

\footnotetext{
${ }^{18} \mathrm{http} / / /$ preview.grid.unep.ch/index3.php?preview=map

${ }^{19} \mathrm{http}: / /$ www.preventionweb.net/english/maps/index.php

${ }^{20}$ UNDP/BCPR: http://www.gripweb.org/grip.php?ido=1003
}

In light of the experience acquired since the launch of the platform in June 2009, different use cases and lessons have been identified.

\subsection{PREVIEW in the disaster management cycle}

During the major earthquake events that occurred in Haiti (January 2010) and in Samoa/Indonesia (September 2009), an important increase in term of data download, map production and web access were observed on the platform. In particular, during the catastrophic event in Haiti, web statistics showed nearly four times more accesses on the portal than the daily mean (450 unique visitors vs. 100) and ten times more data downloaded (around $1 \mathrm{~Gb}$ of data vs. $100 \mathrm{Mo}$ ). This demonstrates that such a platform is probably used to provide general hazards, exposure and risk context for the disaster community and the media. Moreover, the quality of proposed services appears to be suitable as no interruptions have been reported meaning that even when numerous concurrent access occurred, data are still accessible and available. Such observations confirm and reinforce the idea that SDIs together with their geoportals could act as gateways to geospatial information (Masser, 2005b; Mohammadi and Rajabifard, 2009). This allows maximizing the reuse of data and ensuring readily accessible to up-to-date data. Nevertheless, it should be noted that PREVIEW does not intend to be a real-time platform. Apart from the high data resolution, the analysis was conducted using global datasets, whose resolution are not relevant for in-situ planning and should not be used for life and death decisions. However, those global data sets can be used for comparison between countries, or for international agencies to help them prioritizing projects and investments in DRR.

\subsection{Interoperable access to data and metadata}

OGC web services allow users to work in collaboration and offer new opportunities to solve a specific problem. Thus, making data interoperable appears to be a key requirement (Sahin and Gumusay, 2008). In this sense, the open data policy of PREVIEW could act as a catalyst, giving access to all its resources (data as well as metadata) in an interoperable and standardized way and proving the benefits to make data widely available. The act of sharing has the advantage of exposing data to the judgement of the broader community that could in consequence recognize whether or not these data are of sufficient quality. This also gives a possibility to users to provide some feedbacks and, if needed, data providers can improve their data accordingly.

Bernard and Craglia (2005) reported that, in Europe, the most frequent difficulties that could impede an efficient and effective use of data are: getting access to existing data, finding which data are available, data incompatibilities 
and quality issues. A positive sign is that the different OGC web services proposed by the PREVIEW Global Risk Data Platform are progressively used by different organizations: United Nations High Commissioner for Refugees (UNHCR) is accessing data within their own geoportal focused on humanitarian activities, UNEP benefits from data and metadata services for its currently under development Data and Indicators Platform, the UN community through UNSDI activities can also benefit from the availability of these services and the Swiss government accessed PREVIEW metadata through its own metadata catalogue $\left(\mathrm{GeoCat}^{21}\right)$. These examples demonstrate that the difficulties mentioned previously can be mostly overcome by publishing interoperable services and potentially can benefit to other communities that was not envisioned before. Nevertheless a limitation must be highlighted concerning the interoperability. Indeed PREVIEW, by using OGC standards, is syntactically interoperable by allowing the platform to communicate and exchange data with other systems. However, to be fully interoperable, a system must be also semantically and schematically interoperable. Semantic and schematic interoperability gives the ability to interpret the information exchanged meaningfully and accurately, in order to produce useful results. To achieve these levels of interoperability, both sides of the system must define a common and agreed information exchange reference model. This way the content of the information exchanged is unambiguously defined: what is sent is the same as what is understood. The current absence of commonly agreed semantics and schemes to define and represent risk from natural hazards data sets can then impede a full integration. This can create data heterogeneities and result in a waste of time for data analyzers to homogenize data and in consequence negatively influence the quality of the disaster response phase. To achieve such level of interoperability, common agreed frameworks would help data providers to share their data in the most efficient way. The Global Earth Observation System of Systems (GEOSS) and the Infrastructure for Spatial Information in the European Community (INSPIRE) represent two promising frameworks to share and publish data. They provide guidance such as data sharing principles or data specifications that will help data providers to overcome the problems mentioned previously and push data owners to use more open policies and share their data in a fully interoperable way. As stated in the GEOSS 10 Year Implementation Plan (2005a), disaster reduction requires a great effort on data sharing because data are time-sensitive, of known quality, long-term and global by nature. An initiative like GEOSS can facilitate such sharing, enhancing collaboration and coordination between countries and organizations involved in minimizing losses from natural disaster. Contributing to GEOSS not only increases data visibility and wide accessibility to PREVIEW data sets, but also supports and sustains a collaborative effort to move toward a better informed society on reducing disaster risk.

\subsection{Building capacities}

In order to improve the visibility of PREVIEW, to promote the use of OGC standards, to prove the benefits of exchanging and sharing data in an interoperable manner, it is of high importance to build new capacities. For Rajabifard and Williamson (2004), building new capacities through education and research, is certainly the best way to achieve the objective of a wide acceptance and adoption of SDI concepts. This will help to increase endorsement and allows SDIs concepts and related technologies to be widely accepted and adopted. In this regard, PREVIEW is regularly presented and used for demonstrations to different audiences (students, scientists, UN collaborators) allowing people to use it and to gain familiarities with these emerging technologies. The user testing phase and the different demonstrations have clearly highlighted the fact that most users: (1) were looking for "traditional" download options (link to zip files), (2) were not aware of the possibilities offered by OGC web services. Consequently, it was important to offer users the possibility to download data either using a download module and OGC webservices. Nevertheless, once we have shown them what are OGC web services, users appear to be convinced by this new way of accessing data.

Another lesson learnt concerns the process developed to harmonized data. This has shown the necessity to agree on common data models and in our vision it is of high importance to bring such a process at higher level in order to develop standardized data models accepted and used by the overall community. In the case of PREVIEW, the data models were quite easy to develop as it was mostly done with partners that we already know and with which we have been working for a long time.

Finally, the selected open-source approach appears to be a good choice. First because this allows to develop a specific mapping API for our partner agencies that could implement the mapping service into their own web portal. Second, different countries seem to be interested to replicate this platform to publish and share their own data on natural hazards at the national level. This will help UN agencies to support developing countries in learning and taking advantage of SDI concepts and related technologies. It will also improve data accessibility for a better informed and sustainable development.

\footnotetext{
${ }^{21} \mathrm{http}: / /$ www.geocat.ch
} 


\subsection{Limitations and new developments}

One of the issues in providing access to 60 different layers of information with a cartographic web dynamic interface lies in the multiple possibilities of combinations of displayed information. Thus the choice of colours legend schemes was a difficult task. It was sometimes needed to prevent the simultaneous display of different layers to avoid confusion.

The UMN Mapserver and all tested Map Servers do not provide the capacity to turn around the globe, unlike Google earth (sphere) and Google maps (cylinder). The data are provided in a rectangle shape, preventing the display centred, for example, over the Pacific Ocean. This could have been possible by doubling the size of data sets, but this option was finally abandoned (bad performance). This is something that should be improved in the future. Keeping the balance between a user friendly interface and end-users tailored options is a difficult exercise. New developments will include query tools and a search interface for identifying specific events.

\section{Conclusions}

This paper presented the PREVIEW Global Risk Data Platform and described the potential usefulness of a geoportal to facilitate and coordinate data sharing, access and use among different partners. This work also highlighted that sharing spirit, accessibility, availability, interoperability, and data harmonization are important issues that can be clarified with the help of a clearly defined SDI conceptual model. Such a model enhances collaboration and partnership among different participants and gives the possibility to agree on making these data freely available for the benefit of the whole DRR community and beyond.

Geospatial data are essential in disaster cycle of activities and timely access to such data could improve decisionmaking process and thus could save lives and/or minimize losses of property (GEO secretariat, 2005a). Even if damages could not be completely avoided, better coordination and collaboration between organizations as well as better data exchange will help to better identify risk and in the mid to long term, help to reduce losses. With systems that could deliver improved information on natural hazards, this will also help to prevent that such events become disasters. Feeney et al. (2001) argued that SDIs could be seen as an answer to the growing need to organize data across different disciplines and organizations, and helping them address the issue of supporting decision-making process. To achieve this objective, data sharing and open access policies appear to be an important issue allowing an easy and wider usage of data (Craglia et al., 2008). Having the ability to collect data once and reuse it many times is a clear incentive for such initiatives avoiding duplication of time, effort and expenses, and improving access to good quality data and in turn improving decision-making process. In this sense, the PREVIEW Global Risk Data Platform offers the possibility to freely and easily access data that could be useful for preparedness, response and mitigation phases. This work also highlights that facilitating access to data by sharing it in an interoperable and standardized way increases the ease of integration and use. This can support disaster activities and the achievement of a more sustainable development. Moreover, with the help of OGC standards, data are now available and accessible through a wide array of different stakeholders (partner agencies, humanitarian agencies, GEOSS) and by saving time in accessing and integrating data, this could positively influence the disaster response in an emergency situation. Nevertheless, it is urgent to develop data models commonly agreed by the community in order to be interoperable at the syntactic, semantic and schematic levels. It is an indispensable condition to leverage to full potential of interoperability avoiding heterogeneities and positively improving the quality of the disaster response phase.

Finally, it is important to keep in mind that data sharing and related SDI developments rely mostly on individuals that should have in common (1) a sense that better data will lead to better decisions, (2) a sharing spirit that they got something in return and are viewed as collaborative partners and (3) the fact that they are involved in a professional culture that honours serving society and cooperating with others (Craig, 2005). For Arzberger et al. (2004), ensuring that data are easily accessible so that they can be used as often and widely as possible is a matter of sound stewardship of public resources. These authors stated that publicly funded data are a public good, produced in the public interest and thus should be freely available to the maximum extent possible. Based on these considerations, creating harmonized platforms for hazard and risk information to support decision-making processes and allowing data management, distribution and exchange appear to be a necessity.

Acknowledgements. The authors would like to warmly acknowledge the following institutions: United Nations International Strategy for Disaster Reduction (UNISDR), United Nations Development Programme (UNDP), United Nations Environment Programme (UNEP), the Swiss Federal Environment Agency and the University of Geneva for their financial and in kind support in the development of the PREVIEW Global Risk Data Platform and associated research. The authors wish also to thank all data providers and producers who gave access to data during the analysis phase of the project and produced data that are now available on PREVIEW, the complete list of contributors is published in the 2009 GAR report (chapter 2, UN, 2009). The views expressed in this paper are those of the authors and do not necessarily reflect the views of the institutions they belong to.

Edited by: K.-T. Chang

Reviewed by: M. Craglia and another anonymous referee 


\section{References}

Alinia, S. and Delavara, M. R.: Applications of Spatial Data Infrastructure in Disaster Management, Paper presented at the GSDI-11, available at: http://www.gsdi.org/gsdiconf/gsdi11/ papers/pdf/237.pdf (last access: 3 March 2010), 2009.

Arzberger, P., Schroeder, P., Beaulieu, A., et al.: Promoting Access to Public Research Data for Scientific, Economic and Social Development, Data Science Journal, 3, 17 pp., 2004.

Asante, K. O., Verdin, J. P., Crane, M. P., Tokar, S. A., and Rowland, J.: The Role of Spatial Data Infrastructure in the Management of Natural Disasters, Paper presented at the GSDI-9, Santiago, Chile, 2006.

Bernard, L. and Craglia, M.: SDI - From Spatial Data Infrastructure to Service Driven Infrastructure, Paper presented at the First Research Workshop on Cross-learning on Spatial Data Infrastructures (SDI) and Information Infrastructures (II), Twente, The Netherlands, 2005.

Coleman, D. J., McLaughlin, J. D., and Nichols, S.: Building a Spatial Data Infrastructure, Paper presented at the 64th Premanent Congress Meeting of the Fédération Internationale des Géomètres (FIG), Singapore, 1997.

Craglia, M., Goodchild, M. F., Annoni, A., et al.: Next-Generation Digital Earth: A position paper from the Vespucci Initiative for the Advancement of Geographic Information Science, International Journal of Spatial Data Infrastructures Research, 3, 22 pp., 2008.

Craig, W. J.: White Knights of Spatial Data Infrastructure: The Role and Motivation of Key Individuals, URISA journal, 16(2), 5-14, 2005.

Dilley, M., Chen, R. S., and Deichmann, U.: Natural disaster hotspots: a global risk analysis, World Bank Publications, 2005.

European Commission: Directive 2007/2/EC of the European Parliament and the Council of 14 March 2007 establishing an Infrastructure for Spatial Information in the European Community (INSPIRE), Brussels, 14 pp., 2007.

Feeney, M.-E., Rajabifard, A., and Williamson, I.: Spatial Data Infrastructure Frameworks to Support Decision-Making for Sustainable Development, Paper presented at the GSDI-5, Cartagena de Indias, 2001.

GEO secretariat: Global Earth Observation System of Systems 10Year Implementation Plan Reference Document, 209 pp., $2005 \mathrm{a}$.

GEO secretariat: The Global Earth Observation System of Systems (GEOSS) 10-Year Implementation Plan, 11 pp., 2005 b.

GEO secretariat: GEO Capacity building strategy, 13 pp., 2006.

Henricksen, B.: UNSDI Compendium: A UNSDI Vision, Implementation Strategy, and Reference Architecture, UNGIWG, 150 pp., 2007.

Maguire, D. and Longley, P.: The emergence of geoportals and their role in spatial data infrastructures, Comput. Environ. urban, 29(1), 3-14, 2005.

Mansourian, A., Rajabifard, A., Valadan Zoej, M. J., and Williams, D.: SDI for disaster management to support sustainable development. Paper presented at the Map Asia, available at: http://www.gisdevelopment.net/application/natural_hazards/ overview/ma04200.htm (last access: 20 February 2010), 2004.

Mansourian, A., Rajabifard, A., and Valadan Zoej, M. J.: SDI conceptual modeling for disaster management, Paper presented at the ISPRS Workshop on Service and Application of Spatial Data Infrastructure, Hangzhou, China, 2005.
Mansourian, A., Rajabifard, A., Zoej, M., and Williamson, I.: Using SDI and web-based system to facilitate disaster management, Comput. Geosci., 32(3), 303-315, 2006.

Masser, I.: GIS Worlds: Creating Spatial Data Infrastructures, ESRI Press, 2005a.

Masser, I.: The Future of Spatial Data Infrastructures, Paper presented at the ISPRS Workshop on Service and Application of Spatial Data Infrastructure, Hangzhou, China, 2005b.

Masser, I.: Multi-level Implementation of SDIs, GIM International, 20, 4 pp., 2006.

Masser, I.: Building European Spatial Data Infrastructure, ESRI Press, 2007.

Mazzetti, P., Nativi, S., Angelini, V., Verlato, M., and Fiorucci, P.: A Grid platform for the European Civil Protection e-Infrastructure: the Forest Fires use scenario, Earth Science Informatics, 2(1), 53-62, 2009.

Mohammadi, H. and Rajabifard, A.: Multi-source Spatial Data Integration within the Context of SDI Initiatives, International Journal of Spatial Data Infrastructures Research, 4, 18 pp., 2009.

Nebert, D. D.: Developing Spatial Data Infrastructure, The SDI Cookbook, 2005.

Nogueras-Iso, J., Zarazaga-Soria, F. J., Bejar, R., Alvarez, P. J., and Muro-Medrano, P. R.: OGC Catalog services: a key element for the development of Spatial Data Infrastructures, Comput. Geosci., 31(2), 199-209, 2005.

Open Geospatial Consortium: Geospatial Portal Reference Architecture, OGC, 04-039, 23 pp., 2004.

Open Geospatial Consortium: Web Feature Service Implementation Specification, OGC, 04-094, 131 pp., 2005.

Open Geospatial Consortium: OpenGIS Web Map Server Implementation Specification, OGC, 06-042, 85 pp., $2006 \mathrm{a}$.

Open Geospatial Consortium: Web Coverage Service (WCS) Implementation Specification, OGC, 06-083r8, 143 pp., 2006b.

Open Geospatial Consortium: OpenGIS Catalogue Services Specification, OGC, 07-006r1, 218 pp., 2007.

Peduzzi, P., Dao, H., Herold, C., and Mouton, F.: Assessing global exposure and vulnerability towards natural hazards: the Disaster Risk Index, Nat. Hazards Earth Syst. Sci., 9, 1149-1159, doi:10.5194/nhess-9-1149-2009, 2009a.

Peduzzi, P., Deichmann, U., Maskrey, Nadim, F., A., Dao, H., Chatenoux, B., Herold, C., Debono, A., Giuliani, G., and Kluser, S.: Global disaster risk: patterns, trends and drivers, in: Global Assessment Report on Disaster Risk Reduction, United Nations, Geneva, Switzerland, 2009b.

Peduzzi, P. Chatenoux, B., Dao, H., De Bono, A., Deichmann, U., Giuliani, G., Herold, C., Kalsnes, B., Kluser, S., Løvholt, F., Lyon, B., Maskrey, A., Mouton, F., Nadim, F., and Smebye, H.: The Global Risk Analysis for the 2009 Global Assessment Report on Disaster Risk Reduction, Extended summary for the International Disaster and Risk Conference IDRC, Davos 2010, 30 May, 3 June 2010, on-line conference proceedings, available at: http://www.grid.unep.ch/product/ publication/download/peduzzi_etal_IDRC2010.pdf (last access: 10 June 2010), 2010.

Philips, A., Williamson, I., and Ezigbalike, C.: Spatial Data Infrastructure concepts, The Australian Surveyor, 44(1), 8 pp., 1999.

Rajabifard, A.: Diffusion of Regional Spatial Data Infrastructures: with particular reference to Asia and the Pacific, Melbourne, 
University of Melbourne, 2002.

Rajabifard, A. and Williamson, I. P.: Spatial Data Infrastructures: Concept, SDI Hierarchy and Future directions, Paper presented at the Geomatics'80, Tehran, Iran, 2001.

Rajabifard, A. and Williamson, I. P.: SDI Development and Capacity Building. Paper presented at the GSDI-7, Bangalore, India, 2004.

Rajabifard, A., Mansourian, A., Valadan Zoej, M. J., and Williamson, I.: Developing Spatial Data Infrastructure to Facilitate Disaster Management, Paper presented at the GEOMATICS 83, available at: http://www.undp.org.cu/eventos/espacial/SDI_ Disaster_Iran.pdf (last access: 7 April 2010), 2004.

Ryttersgaard, J.: Spatial Data Infrastructure: Developing Trends and Challenges, Paper presented at the International Conference on Spatial Information for Sustainable Development, Nairoibi, 2001.

Sahin, K. and Gumusay, M. U.: Service oriented architecture (SOA) based web services for geographic information systems, Paper presented at the XXIst ISPRS Congress, available at: http://www.isprs.org/congresses/beijing2008/proceedings/2 pdf/5_WG-II-5/03.pdf (last access: 10 December 2009), 2008.
Snoeren, G., Zlatanova, S., Crompvoets, J., and Scholten, H.: Spatial Data Infrastructure for emergency management: the view of the users, Paper presented at the Third International Symposium on Gi4DM, Toronto, 2007.

Tang, W. and Selwood, J.: Spatial portals: gateways to geographic information, ESRI, 2005.

UN: Global Assessment Report on Disaster Risk Reduction, United Nations, Geneva, Switzerland, 207 pp., 2009.

UNDP: Reducing disaster risk: a challenge for development, UNDP global report, United Nations Development Program, New York, 2004.

UNISDR: Hyogo Framework for Action 2005-2015: Building the Resilience of Nations and Communities to Disasters, World Conference on Disaster Reduction, Kobe, Japan, 23 pp., 1822 January 2005.

Weiser, A. and Zipf, A.: Web Service Orchestration of OGC Web Services for Disaster Management, Geomatics Solutions for Disaster Management, 239-254, 2007. 